
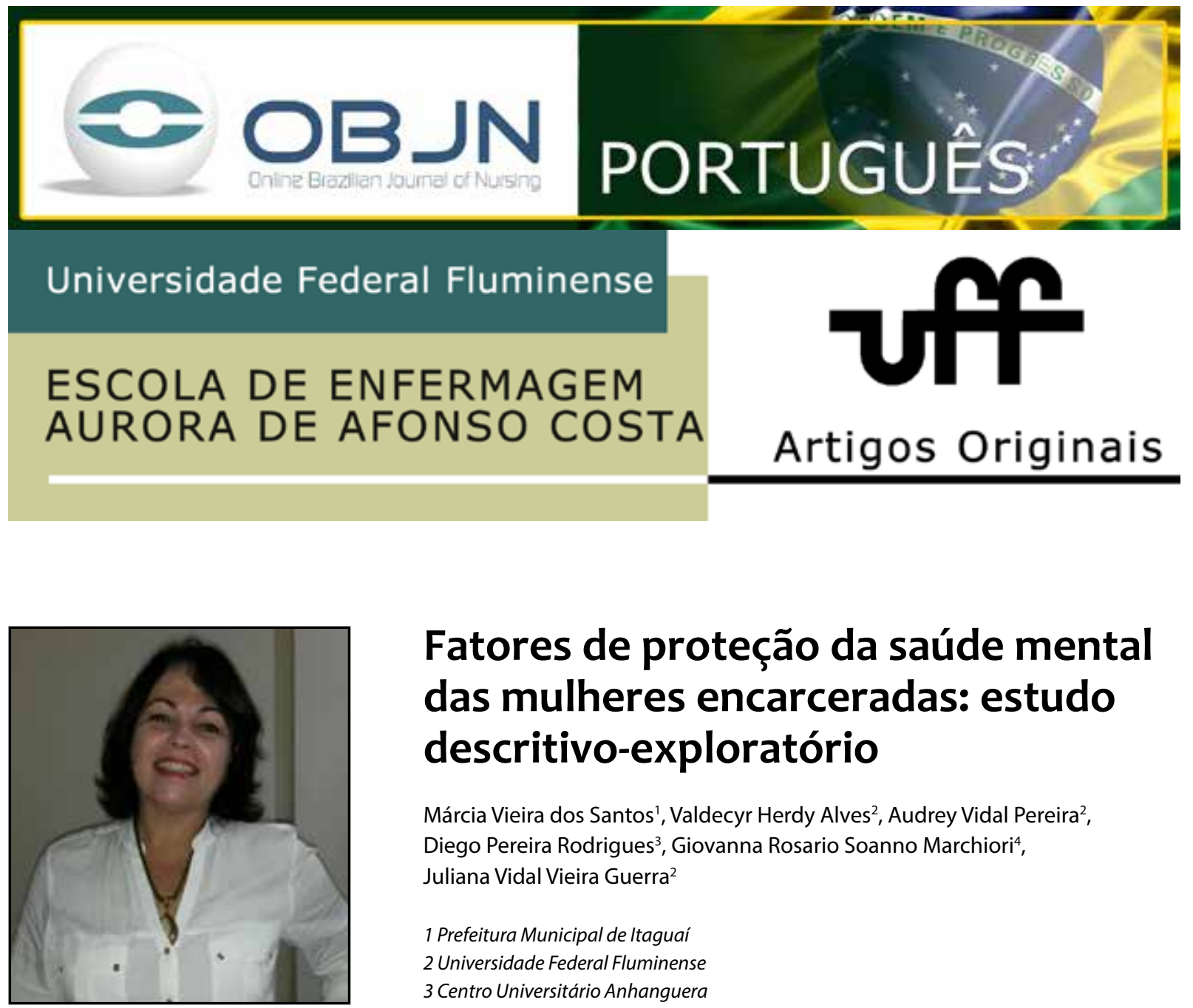

\title{
Fatores de proteção da saúde mental das mulheres encarceradas: estudo descritivo-exploratório
}

\author{
Márcia Vieira dos Santos ${ }^{1}$, Valdecyr Herdy Alves ${ }^{2}$, Audrey Vidal Pereira², \\ Diego Pereira Rodrigues ${ }^{3}$, Giovanna Rosario Soanno Marchiori ${ }^{4}$, \\ Juliana Vidal Vieira Guerra² \\ 1 Prefeitura Municipal de Itaguaí \\ 2 Universidade Federal Fluminense \\ 3 Centro Universitário Anhanguera \\ 4 Faculdade Novo Milênio
}

\section{RESUMO}

Objetivo: identificar as atividades que promovem a saúde mental realizadas pelas mulheres privadas de liberdade, frente às dificuldades encontradas no período de reclusão. Método: estudo descritivo, exploratório, qualitativo, realizado com quarenta mulheres privadas de liberdade em um presídio feminino no estado do Rio de Janeiro, que foram entrevistadas com base em roteiro semiestruturado. Os dados obtidos, submetidos à análise de conteúdo na modalidade temática, ensejaram a categoria Fatores de proteção da saúde mental das mulheres encarceradas. Resultados: as mulheres apontaram como fatores de proteção de sua saúde mental: estudar, trabalhar, realizar atividades de lazer (cantar, conversar, ler) e atividades religiosas. Conclusão: as atividades de promoção à saúde com foco na saúde mental, deve ser repensada com o propósito de assegurar a saúde mental das mulheres privadas de liberdade.

Descritores: Saúde da Mulher; Prisões; Saúde Mental; Promoção da Saúde. 


\section{INTRODUÇÃO}

A sociedade brasileira apresenta diferenças sociais que se tornam evidentes quando o assunto é saúde, especialmente no sistema prisional ${ }^{(1)}$. Estudos recentes demonstram o aumento no aprisionamento de mulheres em vários países, inclusive no Brasil ${ }^{(2)}$, que tem a quarta maior população prisional, ficando atrás apenas dos Estados Unidos, da China e da Rússia. O País apresenta o seguinte quadro: $41 \%$ dos presos ainda aguardam julgamento, 3\% das pessoas privadas de liberdade estão em regime aberto e $15 \%$ estão em regime semiaberto. Essa tendência causa uma superlotação dos estabelecimentos prisionais, expondo um grande número de indivíduos às consequências do encarceramento ${ }^{(3)}$.

O cárcere tem, em sua essência, caráter transformador dos indivíduos. E, nesse objetivo, recorre ao isolamento social, ao trabalho (por vezes imposto em algumas instituições) e às técnicas corretivas. $\mathrm{Na}$ atualidade, no contexto da discussão do retorno desses indivíduos à sociedade, há consenso de que tais medidas são ineficazes, o que os leva à reincidência no crime e consequente regresso à prisão ${ }^{(4)}$, aumentando a sua vulnerabilidade em relação ao ambiente prisional.

Considerando que o sistema penitenciário pode desencadear problemas de saúde ou agravar os preexistentes ${ }^{(5)}$, é importante oferecer condições de confinamento que favoreçam o bem-estar físico e psíquico do indivíduo privado de liberdade, garantindo-Ihe o direito à saúde, conforme determina o Artigo no 196 da Constituição Brasileira.

Um assunto que merece especial atenção pelas suas peculiaridades é a saúde das mulheres privadas de liberdade, em virtude da grande vulnerabilidade dessa população frente a questões relacionadas ao gênero feminino. $E$, consideran- do que a maioria das prisões ditas femininas era espaço masculino que foi adaptada para elas ${ }^{(6)}$ e que a população feminina carcerária vem aumentando consideravelmente, a temática se torna relevante como objeto de estudo.

De acordo com o Sistema Nacional de Informações Penitenciárias, existem 34.058 mulheres encarceradas no Brasil, o que representa 7\% do total da população penitenciária brasileira, havendo um déficit de 13 mil vagas no sistema prisional brasileiro para as mulheres privadas de liberdade ${ }^{(3)}$.

Assim, quando se fala em saúde no âmbito do sistema prisional, a saúde mental é algo preocupante, visto que aumentou o número de pessoas com doenças mentais envolvidas com a justiça criminal brasileira ${ }^{(7)}$. Estudo americano apontou que $75 \%$ das mulheres vivendo em prisões norte-americanas relataram problemas de saúde mental, contra $12 \%$ das mulheres na população em geral( ${ }^{(8)}$, evidenciando que a saúde mental das mulheres encarceradas é mais suscetível ao agravamento decorrente do aprisionamento e da sua história de vida passada e atual ${ }^{(9)}$.

Promover saúde em uma população é identificar suas necessidades e modificar favoravelmente o meio ambiente, reconhecendo que a saúde é o maior recurso para o desenvolvimento social, econômico e pessoal, assim como uma importante dimensão da qualidade de vida ${ }^{(10)}$. No caso das presidiárias, para a efetividade dessa promoção, torna-se necessária uma equipe multiprofissional para programar o direcionamento de ações em saúde, de modo a promover intervenções eficazes e coerentes com as carências do grupo em questão. Ademais, conhecer a quem se está prestando o cuidado é fundamental para o planejamento de ações estratégicas, a implementação e a avaliação do impacto da presença desses profissionais como atuantes na saúde desse grupo(11). 
Diante disso, o estudo teve como objetivo analisar as atividades que promovem a saúde mental realizadas pelas mulheres privadas de liberdade, frente às dificuldades vivenciadas no período de reclusão.

\section{MÉTODO}

Trata-se de pesquisa descritiva, exploratória, com abordagem qualitativa, realizada no período de outubro de 2014 a janeiro de 2015 em uma penitenciária feminina localizada no complexo de Gericinó, bairro de Bangu, Zona Oeste do município do Rio de Janeiro, RJ, Brasil.

Vale esclarecer que para ser autorizada a realização da pesquisa no sistema prisional, a Secretaria de Administração Penitenciária do Estado do Rio de Janeiro exigiu o cumprimento de algumas exigências para a coleta dos dados, a saber: a entrada no presídio só poderia ocorrer após ter sido realizada a conferência cotidiana das presas; a saída teria que ser realizada uma hora antes da conferência das presas, no período noturno; gravações de áudio, filmagem, fotografias e reprodução de qualquer documento foram proibidas no interior do presídio; a assinatura das detentas no Termo de Consentimento Livre e Esclarecido também não foi permitida porque a Secretaria de Administração Penitenciária do Rio de Janeiro não autoriza que sejam disponibilizadas identificação ou informações nominais das pessoas privadas de liberdade, sendo necessária a assinatura do termo pelo supervisor prisional das mulheres, após autorização das participantes. Neste caso, justifica-se a medida sob a alegação de que a Instituição Penal, em nome do Estado, é o órgão responsável por autorizar e se responsabilizar pela participação das encarceradas em atividades que envolvem pesquisas.
A seleção das participantes do estudo foi feita mediante consulta à lista nominal oficial da instituição para identificá-las nos respectivos prontuários no serviço de saúde. Deu-se de maneira aleatória, simples, levando em consideração o final ímpar do número constante no respectivo prontuário, resultando na seleção de 40 mulheres encarceradas.

Essas mulheres foram incluídas a partir dos seguintes critérios: ter prontuário no serviço de saúde; ter interesse em participar das entrevistas para a coleta de dados; estar em condições física e psíquica de fazê-lo; e ter a autorização e a presença das agentes penitenciárias que estivessem de plantão no momento da entrevista. Foram excluídas aquelas que saíram em liberdade, que foram suspensas por motivo de segurança ou transferidas para outra unidade prisional.

A coleta de dados foi realizada a partir de informações que constavam nos prontuários e da técnica da entrevista semiestruturada levada a efeito pela pesquisadora principal no ambulatório de saúde do presídio. As participantes responderam voluntariamente a um roteiro contendo perguntas abertas e fechadas. Previamente ao início das entrevistas, todas as detentas foram informadas acerca do objetivo da pesquisa, sendo-Ihes assegurada a garantia do sigilo do que fosse dito, mediante utilização de um código alfanumérico (M1 ... M40) a ser registrado na respectiva entrevista transcrita e validada.

Nesse sentido, e considerando a impossibilidade de utilizar qualquer meio eletrônico no momento da entrevista, pelos motivos já expostos, a pesquisadora precisou captar e transcrever as respostas aos questionamentos, e depois ler as transcrições para que as entrevistadas pudessem ouvir e demonstrar acordo ou desacordo com a escrita da pesquisadora, que procurou assegurar a precisão das falas das participantes. 
Para realizar a análise e discussão dos resultados, optou-se pela análise de conteúdo na modalidade temática, com o fim de obter informações que expressassem aproximação com a realidade proferida pelas participantes. Foi identificado o núcleo de sentido das entrevistas que, neste estudo, viabilizou a elaboração da construção da seguinte categoria temática: Fatores de proteção da saúde mental das mulheres encarceradas.

A pesquisa foi aprovada pelo Comitê de Ética e Pesquisa da Universidade Federal Fluminense (UFF), sob protocolo $n^{\circ} 696.795 / 2014$, tendo o CAAE n²7061114.3.0000.5243, e autorizada pela Secretaria de Administração Penitenciária do Rio de Janeiro pelo processo E-2108753/2014, assim atendendo a Resolução no 466/2012 do Conselho Nacional de Saúde, que dispõe sobre pesquisa envolvendo seres humanos.

\section{RESULTADOS}

Fatores de proteção da saúde mental das muIheres encarceradas

As mulheres relataram que a sua saúde mental e o sofrimento psíquico durante o período de encarceramento são amenizados por meio de atividades desenvolvidas por elas no ambiente prisional, uma das quais a educação, um determinante social importante para a saúde mental. Em seus relatos, demonstraram grande interesse na participação em atividades educativas dentro do presídio, com satisfação em aprender, diante da possibilidade de novos sonhos e de atualização com o "mundo" fora do presídio, conforme os depoimentos a seguir:

(...) Escola. Não falto aula! Deram-me a grande oportunidade de estudar, o meu sonho era ler e escrever. (M3)
(...) Escola, coisa boa, me faz bem.

Debate as coisas do dia a dia em aula.

Escola é um veículo de comunicação atual. (M12)

Quanto ao trabalho ofertado às presas pelo sistema penitenciário, ele tem a função de ocupar o tempo ocioso e permitir a remissão da pena. Foi observada a satisfação das entrevistadas em trabalhar para "ocupar" a mente, conforme relatado:

(...) O meu trabalho que me ajuda bastante aqui dentro. (M5)

(...) Eu lavo roupa e faço faxina, ocupo a minha mente. (M9)

(...) Acabo a faxina, e espero cair a noite e faço faxina na sela. (M16)

Apesar de as mulheres manifestarem grande interesse nas atividades educativas e laborais dentro do presídio, o trabalho está dissociado da educação, ou seja, as mulheres trabalham ou estudam, e isto é demonstrado nos depoimentos a seguir:

(...) Quem trabalha, não estuda. (M2)

(...) Já estudei, saí da escola para trabaIhar. (M12)

(...) Estou trabalhando, não faço curso. (M19)

Outra situação encontrada foi que algumas mulheres, como as gestantes e as idosas, não podiam trabalhar, como referido nos depoimentos:

(...) Pedi ao juiz para trabalhar e fiz vários cursos. $\mathrm{O}$ idoso não tinha direito a 
trabalhar. A partir dos 60 anos não se trabalhava. (M29)

(...) Grávida não faz curso, nem trabalha. (M33)

O lazer contribui para a qualidade de vida da mulher. O que a instituição estudada oferece às presas é o banho de sol, que ocorre em ambiente aberto, com horários predeterminados e supervisionado pelas agentes penitenciárias, quando podem ser realizadas atividades físicas em grupo ou individualmente. Contudo, as entrevistadas não demonstraram interesse no banho de sol, conforme relataram:

(...) Não gosto. Não gosto muito de sol. (M5)

(...) Há muito tempo que não tomo. Quando tem, não quero ir. (M10)

(...) Nunca. Se fui duas vezes, foi muito, não gostei. (M13)

Em seus depoimentos, as entrevistadas apontaram o lazer preferido:

(...) Ocupo a mente lendo. Amo leitura, música. (M2)

(...) Converso, deito, discuto, brinco com a companheira. Ela me ajuda a passar o tempo. (M5)

(...) Vejo TV, leio. Estou catalogando os livros da biblioteca. (M32)

(...) Fico sentada no refeitório, canto e oro. (M38)
As atividades religiosas, através dos relatos das entrevistadas, são consideradas momentos de bem-estar, benéficos para a saúde mental das mulheres, sendo um mecanismo de sobrevivência dentro do sistema prisional:

(...) Vou ao culto (...) sempre quando tem. Vou sempre que posso. Sinto-me confortável com a Palavra. (M19)

(...) Vou ao culto, eu gosto. Gosto do Evangelho. (M26)

(...) Vou ao culto duas vezes por semana, me sinto bem. (M33)

(...) Deus me colocou aqui dentro para refletir, para que eu lá fora seja uma nova mulher. (M36)

(...) Vou pagar o que eu errei, eu vou tirar minha cadeia com equilíbrio, com Deus. Na rua eu conhecia Deus como cultura. Mas Deus pode tocar, eu sinto isto aqui. (M40)

Apesar de algumas entrevistadas não frequentarem nenhum culto religioso, elas demonstraram buscar conforto espiritual por meio da oração:

(...) Não vou, não tem dia nem horário (cultos religiosos), oro sozinha, falo com Deus. Gosto muito do Evangelho. (M12)

(...) Oro, leio muito a Bíblia. (M22)

(...) Oro bastante, me tranquilizo. (M35)

Muitas entrevistadas têm consciência de que precisam fazer"algo" para prevenir o adoeci- 
mento mental, e para isto desenvolvem algumas atividades que as fazem sentirem-se bem, como se depreende nos depoimentos a seguir:

(...) Previno-me de muitas coisas, trabalho meu psicológico, ele comanda o corpo todo. (M8)

(...) Escrevendo não me adoece, faço carta para minha casa, para o meu marido. (M17)

(...) A primeira vez que cheguei à prisão, olhei a quentinha, coloquei na boca e lembrei-me da minha comida. É desta que me alimento. Trabalho minha mente. (M29)

(...) Tento conversar bastante, para esquecer, evito ficar sozinha. (M34)

Estas constituem algumas das atividades desenvolvidas pelas mulheres no sistema prisional a fim de promover sua saúde mental, e que acabam sendo um fator de proteção para o adoecimento, diminuindo o sofrimento psíquico dentro do ambiente carcerário.

\section{DISCUSSÃO}

As mulheres encarceradas demonstraram que algumas atividades desenvolvidas por elas trazem satisfação tornando-se, portanto, fatores de proteção da saúde mental, já que as mantém mais saudáveis psiquicamente no período de reclusão. As atividades citadas por estas mulheres abrangem trabalho, educação, religião, leitura, fazer amizades, escrever, escutar música, interagir com as companheiras e frequentar cultos religiosos buscando conforto espiritual, sendo consideradas mecanismos que as protegem do adoecimento mental, já que a saúde é um direito também das mulheres privadas de liberdade que deve ser garantido, conforme determina a Constituição Brasileira.

Quanto à importância do papel da educação e do trabalho no cárcere, fica claro que ambas as atividades devem englobar, necessariamente, os aspectos que envolvem a construção da imagem da mulher ${ }^{(12)}$ qualificando-as para o mercado de trabalho quando estiverem em liberdade. Mas, deve-se destacar que o trabalho no cárcere é uma atividade cujo retorno efetivo para a vida em sociedade é bastante restrito ${ }^{(13)}$.

Apesar dos benefícios relatados pelas entrevistadas acerca do trabalho e da educação para a preservação da saúde mental no sistema penal, existem algumas situações avaliadas, neste trabalho, de presas excluídas dessas atividades, como é o caso das gestantes, que não trabalham nem estudam, e da idosa, que não pode trabalhar, fazendo com que fiquem ociosas e em isolamento, o que dificulta o cotidiano prisional e favorece o sofrimento crônico que leva ao desconforto psíquico. Não é demais lembrar que a preservação da saúde mental das encarceradas também passa pela perspectiva da cidadania(14).

Outra posição avaliada foi a de quem trabalha não estuda, isto é, as duas situações não acontecem. Ou se trabalha ou estuda. Entendendo que os dois fatores protegem a saúde mental e dão satisfação para estas mulheres, por que não repensar essa prática dentro do sistema carcerário? É válido enfatizar que várias pessoas na sociedade trabalham e estudam e, então, por que não oferecer as mesmas condições às muIheres encarceradas? A percepção que se deve ter é a de que estas atividades têm o objetivo de promover saúde mental e favorecer a inserção dessas mulheres no mercado de trabalho quando estiverem em liberdade. 
As atividades que promovem a qualidade de vida mental e física, a inclusão social, a cidadania e o desenvolvimento humano, são realizadas por meio do esporte e do lazer ${ }^{(15)}$. No Brasil, em 2003, de acordo com a Lei no 10.79214, Art. 52 $\S 4$, "todo preso terá direito à saída da cela por duas horas diárias para banho de sol"; e em 2014, a Política Nacional de Atenção às Mulheres em Situação de Privação de Liberdade e Egressas do Sistema Prisional (PNAMPE) ${ }^{(16)}$, Art. 30, garantiu à mulher privada de liberdade a possibilidade de desfrutar de lazer na instituição prisional. Contudo, as entrevistadas não demonstraram interesse no banho de sol, atividade oferecida pelo sistema penitenciário em um local aberto, com dia e hora para acontecer.

Segundo o Plano Nacional de Políticas para as Mulheres, para as mulheres em geral, o lazer é visto como uma atividade relacionada com a família, ao lado das crianças, e quase sempre restrita ao espaço doméstico, pouco ou nada se diferenciando da rotina. $E$, para esse plano, é necessário valorizar e promover as iniciativas e a produção cultural das mulheres, a participação delas na preparação e na realização de eventos esportivos, lembrando ainda que o sedentarismo também contribui para os problemas de saúde ${ }^{(15)}$.

Como é preciso estímulo para que as muIheres desenvolvam atividades físicas, o banho de sol proporcionado pelo presídio feminino necessita ser reestruturado, e deve ser organizado por profissionais especializados, que organizem este lazer através de práticas saudáveis e promovam mudança de hábitos das detentas. A propósito, as mulheres encarceradas relataram lazer quando realizavam outras atividades que Ihes proporcionavam mais satisfação, como ler, conversar com as amigas, ver televisão, cantar, orar e trabalhar, que lhes trazem um equilíbrio mental. Faz-se necessário, portanto, repensar o que significa lazer para o sexo feminino dentro do sistema penal, e dispensar uma atenção mais criteriosa sobre a questão de gênero no cárcere, atentando ainda mais para suas peculiaridades e necessidades ${ }^{(13)}$.

Em relação à religião, ela foi avaliada como uma atividade que traz satisfação e oferece um suporte emocional para as entrevistadas. Nesse contexto, a conversão religiosa para melhorar a autoimagem das detentas funciona como uma estratégia de adaptação à institucionalização(14).

É importante ressaltar que existem diferenças entre os construtos religião, religiosidade e espiritualidade: a religião é o sistema organizado de crenças, rituais e símbolos que facilitam o acesso ao sagrado; a religiosidade refere-se a quanto o indivíduo acredita e segue uma religião; e a espiritualidade diz respeito à busca pessoal de compreensão, relacionada a questões existenciais e suas relações com o sagrado ${ }^{(17,18)}$. Desse modo, as mulheres privadas de liberdade buscam, por meio dos cultos religiosos, expressar a sua espiritualidade com o propósito de resguardar a própria saúde mental, constituindo-se em fator de proteção pessoal contra o adoecimento.

A assistência religiosa tem um papel importante na melhora da saúde mental de um indivíduo dentro da prisão, seja homem ou mulher, isto porque ela oferece um suporte emocional diante dos sofrimentos e privações específicas ${ }^{(19)}$. Assim, a assistência religiosa deve ser estimulada entre as detentas, pois ajuda amenizar a situação emocional dessa população(20).

Pelo exposto, pode-se inferir que as próprias entrevistadas adotam medidas que lhes parecem as mais corretas para o enfrentamento de transtornos psíquicos, o que deve ser respeitado pelas autoridades no âmbito prisional.

\section{CONCLUSÃO}

Conhecendo as atividades desenvolvidas pelas entrevistadas com a finalidade de pro- 
mover a própria saúde mental no período de encarceramento, considera-se que é possível repensar as ações realizadas dentro dos presídios femininos, tendo como objetivo a prevenção do sofrimento psíquico dessas mulheres, entendendo-se que as especificidades do gênero devem ser consideradas como um dos determinantes de saúde para formulação de políticas públicas. Essas devem enfocar prioritariamente a promoção e a prevenção de agravos à saúde mental dessa população que, quando encarcerada, fica muito mais vulnerável ao adoecimento psíquico.

Por meio de políticas públicas elaboradas especificamente para o sistema penitenciário, almeja-se a transformação das condições de vida dessa população nesse ambiente. Contudo, promover saúde não é responsabilidade exclusiva do setor saúde, e sim de diversos setores, como o político, o econômico, o social, o cultural, o ambiental, o comportamental e o biológico. Promover saúde é garantir um estilo de vida saudável, um bem-estar global. Nesse sentido, é necessário que gestores, profissionais de saúde, agentes penitenciários, mulheres encarceradas e todos os atores envolvidos nesse processo entendam que as atividades de ocupação no cárcere não devem ser apenas mais uma tarefa para que a mulher encarcerada ocupe o seu tempo ocioso, mas fazer parte de um projeto com atividades específicas, direcionadas a essa população e às suas reais necessidades, de modo que sejam capazes de promover a saúde mental no âmbito do sistema penitenciário feminino.

\section{REFERÊNCIAS}

1. Kolling GJ, Silva MBB, Sá MCDNP. Direito à Saúde no Sistema Penitenciário. Rev Tempus Acta Saúde Col [internet]. 2013 [cited 2015 nov 2015]. 7(1): 291-8. Available from: http://www. tempusactas.unb.br/index.php/tempus/article/ view/1304/1133

2. Oliveira LV, Costa GMC, Medeiros KKAS, Cavalcanti AL. Epidemiological profile of female detainees in the Brazilian state of Paraíba: a descriptive study. Online Braz J Nurs (Online) [Internet]. 2013 [cited 2015 nov 2015]. 12(4): 892--901. Available from: http://www.objnursing.uff.br/index.php/ nursing/article/view/4284/pdf_35

3. Brasil. Ministério da Justiça. Departamento Penitenciário Nacional. Levantamento Nacional de Informações Penitenciárias. Brasília; 2014.

4. Scherer ZAP, Scherer EA, Nascimento AD, Ragozo FD. Sociodemographic profile and penal history of the prison population at a female penitentiary in the interior of São Paulo state. SMAD, Rev. eletrônica saúde mental alcool drog [internet]. 2011 [cited 2015 nov 2015]. 7(2): 55-62. Available from: http://www.revistas.usp.br/smad/article/ view/49572/53686

5. Geniole LAI, Kodjaoglanian VL, Vieira CCA. A saúde da família em populações carcerárias. Fiocruz Unidade Cerrado Pantanal [internet]. 2011 [cited 2015 nov 2015]. Available from: http:// www.saudedafamilia.ufms.br/manager/titan. php?target $=$ openFile\&fileld $=354$

6. Brasil. Ministério da Justiça. Departamento Penitenciário Nacional. Relatório Final do I Encontro de Planejamento do Projeto Efetivação dos Direitos das Mulheres no Sistema Penal. Brasília; 2012.

7. Silva NC, Rosa MI, Amboni G, Mina F, Comim CM, Quevedo J.Transtornos psiquiátricos e fatores de risco em uma população carcerária. ACM arq catarin med [internet] 2011 [cited 2015 nov 2015].40(1): 72-6. Available from: http://www. acm.org.br/revista/pdf/artigos/850.pdf

8. Kramer K, Comfort M. Considerations in HIV prevention for women affected by the criminal justice system. Women's Health Issues [internet]. 2011 [cited 2015 nov 2015]. 21(6): S272-S277. Available from: http://www.ncbi.nlm.nih.gov/ pubmed/21782463

9. Canazaro D, Argimon, IIL Características, sintomas depressivos e fatores associados em mulheres encarceradas no Estado do Rio Grande do Sul, Brasil. Cad saúde pública [internet]. 2010 [cited 2015 nov 2015]. 26(7): 1323-33. Available from: http://www.scielo.br/pdf/csp/v26n7/11.pdf

10. Czeresnia D, Freitas CM. Promoção da Saúde: 
conceitos, reflexões, tendências. $2^{\mathrm{a}}$ ed. Rio de Janeiro: Fiocruz; 2011.

11. Ribeiro SG, Lessa PRA, Monte AS, Bernardo EBR, Nicolau AIO, Aquino PS, et al. Gynecologic and obstetric profile of state imprisoned females. Texto contexto enferm [internet] 2013 [cited 2015 nov 2015]. 22(1): 13-21. Available from: http:// www.scielo.br/pdf/tce/v22n1/02.pdf

12. Cunha EL. Ressocialização: o desafio da educação no sistema prisional feminino. Cad. CEDES [internet] 2010 [cited 2015 nov 2015]. 30(81): 157-78. Available from: http://www.scielo.br/pdf/ccedes/ v30n81/a03v3081.pdf

13. França MHO. Criminalidade e prisão feminina: uma análise da questão de gênero. Revista Ártemis [internet] 2014 [cited 2015 nov 2015]. 18(1): 212-27 Available from: http://periodicos.ufpb.br/ ojs/index.php/artemis/article/view/22547/12510

14. Lima GMB, Neto AFP, Carvalho PD, Amarante PDC, Filha MOF. Mulheres no cárcere: significados e práticas cotidianas de enfrentamento com ênfase na resiliência. Saúde em Debate [internet] 2013 [cited 2015 nov 2015]. 37(98): 446-56. Available from: http://www.scielo.br/pdf/sdeb/v37n98/ a08v37n98.pdf

15. Brasil. Ministério da Saúde. Secretaria de Políticas para as Mulheres. Plano Nacional de Políticas para as Mulheres. Brasília; 2013.

16. Brasil. Ministério da Saúde. Portaria Interministerial n²10, de 16 de janeiro de 2014. Brasília, 2014.

17. Felipe AOB, Carvalho AMP, Andrade CUB. Spirituality and religion as protectors for adolescent drug use. SMAD, Rev. eletrônica saúde mental alcool drog [internet]. 2015 [cited 2015 nov 2015]. 11(1): 49-58. Available from: http://pepsic.bvsalud.org/ pdf/smad/v11n1/08.pdf

18. Ribeiro FML, Minayo MCS. O papel da religião na promoção da saúde, na prevenção da violência e na reabilitação de pessoas envolvidas com a criminalidade: revisão de literatura. Ciênc. saúde coletiva [internet]. 2014 [cited 2015 nov 2015]. 19(6): 1773-89. Available from: http:// www.scielosp.org/pdf/csc/v19n6/1413-8123csc-19-06-01773.pdf
19. Pereira DA, Marques MF, Hubner CVK, Silva KJF. Sintomas depressivos e abuso de drogas entre mulheres presas na cadeia pública feminina de Votorantim/SP. Rev Facul Ciênc Méd de Soroc [internet]. 2014 [cited 2015 nov 2015]. 16(2): 715. Available from: http://revistas.pucsp.br/index. php/RFCMS/article/view/13423/pdf

20. Silva JF. Uma reflexão sobre a possibilidade de aplicação efetiva e real dos direitos humanos aos presos. Segur pública \& Cidadan [internet] 2012 [cited 2015 nov 2015]. 3(2): 43-78. Available from: https://periodicos.dpf.gov.br/index.php/RSPC/ article/view/100/103

Todos os autores participaram das fases dessa publicação em uma ou mais etapas a seguir, de acordo com as recomendações do International Committe of Medical Journal Editors (ICMJE, 2013): (a) participação substancial na concepção ou confecção do manuscrito ou da coleta, análise ou interpretação dos dados; (b) elaboração do trabalho ou realização de revisão crítica do conteúdo intelectual; (c) aprovação da versão submetida. Todos os autores declaram para os devidos fins que são de suas responsabilidades o conteúdo relacionado a todos os aspectos do manuscrito submetido ao OBJN. Garantem que as questões relacionadas com a exatidão ou integridade de qualquer parte do artigo foram devidamente investigadas e resolvidas. Eximindo, portanto o OBJN de qualquer participação solidária em eventuais imbróglios sobre a matéria em apreço. Todos os autores declaram que não possuem conflito de interesses, seja de ordem financeira ou de relacionamento, que influencie a redação e/ou interpretação dos achados. Essa declaração foi assinada digitalmente por todos os autores conforme recomendação do ICMJE, cujo modelo está disponível em http://www. objnursing.uff.br/normas/DUDE_final_13-06-2013.pdf

Recebido: 05/04/2016

Revisado: 31/01/2017

Aprovado: 02/02/2017 